OPEN ACCESS

Edited by:

Mariella Pazzaglia,

Sapienza University of Rome, Italy

Reviewed by:

Satoshi Nobusako,

Kio University, Japan

Jean-Paul G. Noel,

New York University, United States

${ }^{*}$ Correspondence:

Josselin Baumard

josselin.baumard@univ-rouen.fr

Specialty section:

This article was submitted to

Cognitive Neuroscience,

a section of the journal

Frontiers in Human Neuroscience

Received: 30 May 2019

Accepted: 26 August 2019

Published: 11 September 2019

Citation:

Baumard J and Osiurak F (2019) Is

Bodily Experience an Epiphenomenon of Multisensory Integration and

Cognition?

Front. Hum. Neurosci. 13:316. doi: 10.3389/fnhum.2019.00316

\section{Is Bodily Experience an Epiphenomenon of Multisensory Integration and Cognition?}

\author{
Josselin Baumard $^{1 *}$ and François Osiurak ${ }^{2,3}$ \\ ${ }^{1}$ Normandie Univ, UNIROUEN, CRFDP (EA7475), Rouen, France, ${ }^{2}$ Laboratory for the Study of Cognitive Mechanisms (EA \\ 3082), University of Lyon, Lyon, France, ${ }^{3}$ French University Institute, Paris, France
}

Keywords: action, bodily awareness, body schema, body image, epistemology, multisensory integration, sense of ownership, sense of agency

\section{INTRODUCTION}

Having a physical body is not sufficient to experience the feeling of having a body. This somewhat staggering assumption has long been demonstrated by studies on phantom limbs (Ramachandran, 1998), distortions of body image following right brain damage (Hécaen and Ajuriaguerra, 1952), and experimentally induced body illusions (Botvinick and Cohen, 1998; Petkova and Ehrsson, 2008). A critical issue is now to understand which mechanisms underlie bodily experience (de Vignemont, 2010), a prerequisite to develop studies on tool incorporation, and neurorehabilitation. That being said, the orientation of research strongly depends on the selected epistemological options. The present work aims at discussing two epistemological options, one being representational (i.e., bodily experience relies on the activation of specific cognitive modules devoted to body representations), and the other being structuralist (i.e., bodily experience is an epiphenomenon of both multisensory integration and cognition).

\section{DEFINING BODY SCHEMA AND BODY IMAGE}

Classical taxonomies (Sirigu et al., 1991; Schwoebel and Coslett, 2005) have made a distinction between three body representations. First, the body schema is an immediate sensorimotor representation that specifies the relative positions of body parts in space over time (Buxbaum, 2001). Second, body semantics are of conceptual and linguistic nature, and describe the functions and categories of body parts (e.g., both the wrist and elbow are joints). Third, the body structural description is mainly of visual nature and provides individuals with knowledge on the normal structure of the body (e.g., relative positions of body parts; Goldenberg, 1995). It is a long-term body representation that may also be broken down into a general body image (e.g., knowing that all humans have two arms) and an individual body image (i.e., the stable representation of one's own body over time). The latter implies that individual experience plays a key role in body representation (i.e., the habitual body; Merleau-Ponty, 1945). Due to the conceptual ambiguity of these concepts (de Vignemont, 2010), we shall use the "bodily experience" label as a whole category encompassing body schema and body image and, more generally, the experience of having a body.

\section{EPISTEMOLOGICAL ISSUES}

The abovementioned taxonomy admits that distinct cognitive modules are devoted to specific body representations. Nevertheless, "there are so many bodily disorders, and therefore so many possible dissociations, that one would end up with an almost infinite list of body representations" 
(de Vignemont, 2010, p. 7). In this view, the virtually infinite multiplication of cognitive modules would result in unfalsifiable theories of bodily experience (see also De Vignemont, 2007). It follows that a scientific theory should rely on a limited number of cognitive modules. However, if that is so, why are there so many different bodily disorders (de Vignemont, 2010)? Perhaps one solution would be to consider theoretical options of structuralism, an epistemological account initially developed in linguistics (De Saussure, 1915), and anthropology (LéviStrauss, 1958), and occasionally applied to neurological patients (Sabouraud, 1995).

The main assumptions of structuralism are as follows. (1) The human mind consists of a minimum set of modular components (i.e., the structure), the number of which is limited by their universality (e.g., all humans are capable of language independently of the multiplicity of languages). This is consistent with the modularity and universality of mind assumed in cognitive psychology (Marr, 1982; Fodor, 1983). However, (2) the diversity of individual experiences does not reflect the activity of specific cognitive modules but rather is incidental and conjuncture-dependent: Different individual experiences may lead to infinite variations of individual psychological conformations (e.g., the painting), and yet the underlying structure should be the same across individuals (e.g., the canvas). (3) Components of the mind are interdependent rather than independent, sequential and hierarchical. "Heterarchy" may better reflect the complexity and non-linearity of brain activity (Fuster, 2009). (4) By contrast with strict modularity, sensations are processed by all of the components simultaneously (e.g., one familiar tool is simultaneously the object of both semantic and technical reasoning; Osiurak, 2014). This amounts to considering that components of the mind interfere with one another (i.e., the interference hypothesis) in the construction of phenomena (e.g., human written language may result from the interaction of language and technics; Gagnepain, 1990). On this account, perhaps bodily experience does not reflect specific body representations, but rather results from the interaction of all human cognitive skills (Figure 1).

\section{IMPLICATIONS FOR THEORIES OF BODILY EXPERIENCE}

Even though structuralism is questionable for being too holistic, over the past few years embodied cognition experiments provided data consistent with the interference hypothesis. But before demonstrating relationships between bodily experience and any cognitive mechanism, it is necessary to delineate specific neurological mechanisms underlying bodily experience. In this regard, it is argued that multisensory integration is a prerequisite to experiment the unity and continuity of the body and self, and that interference with additional cognitive dimensions may underlie various body-related phenomena.

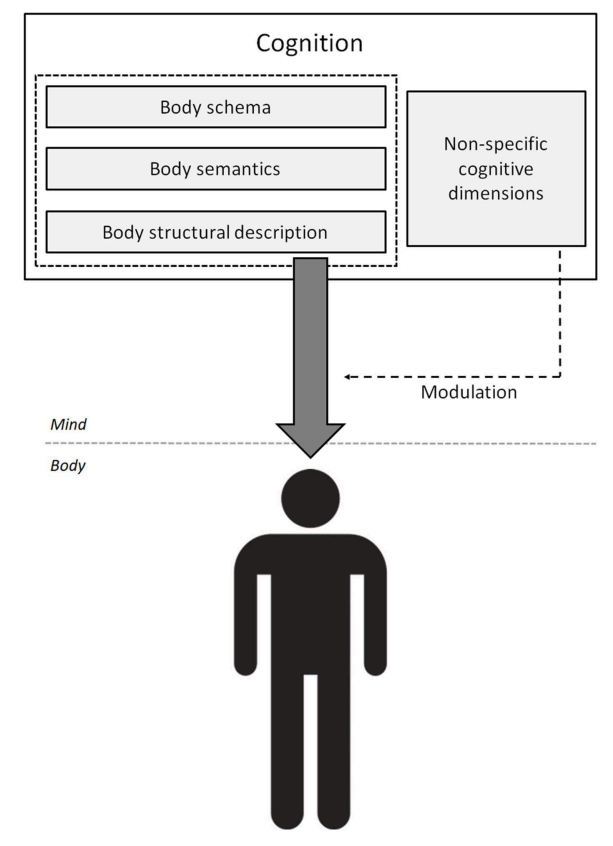

A

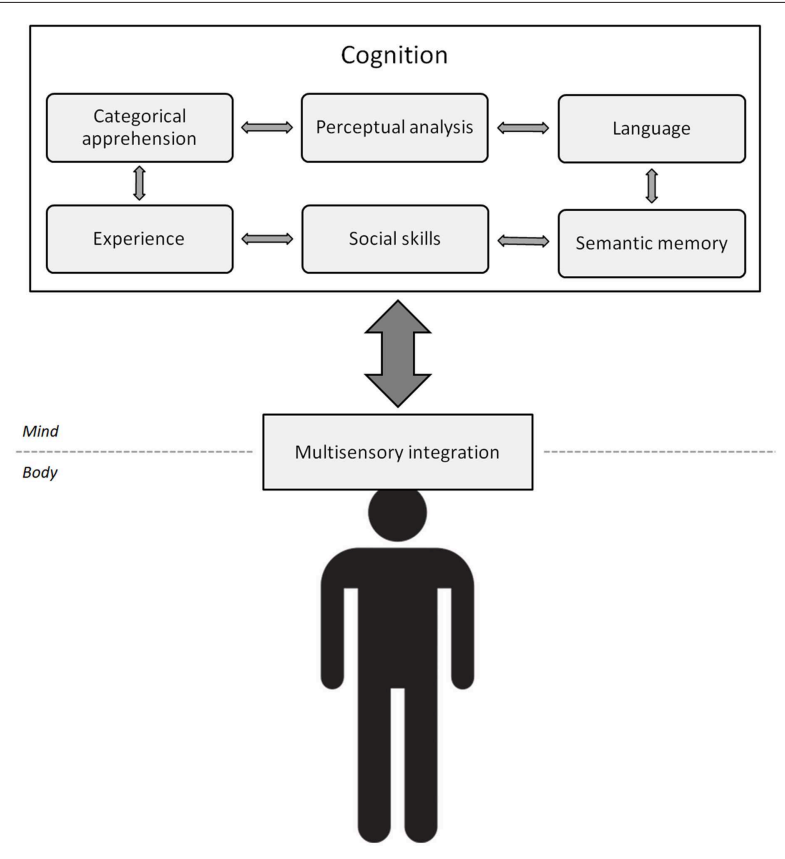

B

FIGURE 1 | Two epistemological accounts of bodily experience. (A) The cognitive account of bodily experience. Specific body representations determine bodily experience, while additional, non-specific cognitive components modulate the expression of these representations. (B) The structuralist account of bodily experience. There are no body-specific representations. Instead, all of the cognitive processes (not necessarily body-specific) interfere with multisensory integration, which results in bodily experience. Cognitive dimensions also interact with each other (small gray bidirectional arrows), resulting in various phenomena. Adopted from https:// pixabay.com/fr/service/license/. 


\section{Multi-Sensory Integration as a Body-Specific Process?}

Before the advent of cognitive architectures, bodily experience has long been viewed by neurologists as an epiphenomenon of multisensory integration (i.e., the combination of sensations arising from different modalities and brain regions; Bonnier, 1905; Head and Holmes, 1911; see also de Vignemont, 2010; Longo and Haggard, 2012a,b). The latter is at the root of body unity (e.g., one can perceive her/his hand as a unitary body part because she/he sees and feels it at the same point in space) and makes it possible to distinguish between self and non-self (e.g., objects, others) stimulations. More recent body illusion experiments have revived and extended this multisensory account of body ownership (Botvinick and Cohen, 1998; Petkova and Ehrsson, 2008).

Multisensory integration depends on the activity of multiple brain regions including the sensory, premotor, posterior parietal, temporal superior, and internal cortex (Wiener, 1996; Calvert and Thesen, 2004; Petkova et al., 2011a; Ursino et al., 2014; Yau et al., 2015). Remarkably, these regions are not specific to bodily experience for they are also involved in cognitive functions like memory, visuospatial, praxis, and social skills. It is then plausible that these brain regions are actually not body-specific but contribute to bodily experience.

\section{Cognition and the Body}

This section enumerates, non-exhaustively, findings/hypotheses that are in line with the interference hypothesis (i.e., the interaction between cognition and bodily experience).

\section{Bodily Experience and Perceptual Analysis}

It has long been assumed that body schema/image is independent from perceptual analysis. Nevertheless, well-known works have demonstrated that the physical characteristics of the body have an impact on visuospatial analysis (Proffitt, 2006). Likewise, motor imagery (i.e., the ability to mentally simulate movements of specific body parts) presumably involves the body schema but is sensitive to peripheral bodily conditions like chronic pain (Breckenridge et al., 2019). Therefore, body representations seem to be highly dependent on immediate bodily experience, and it is no longer possible to admit full independence between personal, and extrapersonal perception.

\section{Bodily Experience and Action}

In the field of apraxia, categorical apprehension (i.e., the ability to select and combine parts of multipart objects into a whole configuration) deficits may account for both apraxia of tool use and visuo-imitative apraxia (Goldenberg, 2009), two disorders that have been explained by either body schema (Buxbaum, 2001), or body image deficits (Goldenberg, 1995). Remarkably, categorical apprehension may be the direct psychological expression of the particular neuronal architecture of the left parietal lobe (rather than a specific cognitive module), which is why it may apply to both body, and non-body stimuli indiscriminately (i.e., body parts and objects). In the same vein, technical reasoning (i.e., the ability to infer tool/object characteristics that are relevant to achieve a given goal; Osiurak,
2014) might condition the selection of body parts during action (e.g., one may use her/his nails to play scratch-card games because nails have the same properties as coins to achieve the goal of scratching).

\section{Bodily Experience and Language}

Interestingly, a similar differentiation/combination function prevails in the field of linguistics (De Saussure, 1915), and presumably underlies categorization and concept formation (i.e., the ability to identify and group recurrent information across infinite experiences; Vallila-Rohter and Kiran, 2015). It is not surprising then, that correlations are frequently observed between gestures conveying meaning on the one hand, and language on the other hand (Vingerhoets et al., 2013). Actually, many works consistently demonstrated the bidirectional relationships between language and the body, especially action (Schwartz et al., 2008; Shebani and Pulvermüller, 2018), and body part localization (Mattioni and Longo, 2014). Perhaps bodily experience not only develops under the influence of language, but also varies greatly in everyday life by the mere fact of thinking and talking.

\section{Bodily Experience and Semantic Memory}

Broadly speaking, body semantics correspond to knowledge about the body and are independent from the body schema. Nevertheless, these representations are more intermingled than expected. Conceptual knowledge on body parts grows as a function of their involvement in action (Auclair Jambaqué and Jambaqué, 2015), and children with spinal cord injury may show selective deficits of body image (Salvato et al., 2017). It follows that body semantics are not the mere result of explicit, didactic learning but also of embodied, individual experience. The fact that body image can be selectively impaired in adults can be understood as an effect of culture-dependent brain plasticity. After all, partially different brain regions may underlie English and Greek in bilingual individuals and yet, they are not the expression of completely different cognitive processes (Ekiert, 2003). This embodied account of body image predicts that actionbased tasks should be as efficient as semantic-based tasks in the rehabilitation of body image deficits.

\section{Bodily Experience and Social Skills}

Another property of semantic memory-and hence body semantics-is that it is a shared, collective memory acquired through social interactions. The fact that similar brain regions represent the self and others (Kruse et al., 2016) supports the hypothesis of a socially grounded bodily experience. Besides, the observation of others shapes the multisensory peripersonal space (Pellencin et al., 2018). Likewise, the estimated metrics of someone else's body depends on social features like gender (Linkenauger et al., 2017). In this regard, it is likely that attitudes toward social partners influence bodily experience, especially since the emotional valence of stimuli has an influence on movement control (so, perhaps, on body schema; Esteves et al., 2016). This might imply that the quality of the relationship between a patient and its physical therapist have a direct effect 
on rehabilitation, in that positive attitudes toward the therapist may reconfigure peripersonal space in itself.

\section{Bodily Experience and Individual Experience}

Studies on body-swapping illusions (Petkova and Ehrsson, 2008) have demonstrated that they are limited (de Vignemont and Farnè, 2010): The illusion does not work with objects that are not body-shaped, and the feeling of owning the new body occurs only from a 1st person perspective (Petkova et al., 2011b). Nevertheless, with regard to the plasticity of perception (Sachse et al., 2017), it is probably because we are used to experiment our body in a 1st person perspective (i.e., the habitual body). Indeed, body-related tasks are influenced by both individual habits (Isaac and Marks, 1994), and the experience of either the first or the third perspective (Edwards et al., 2019). Contrary to long-standing beliefs, there may be no limit to the plasticity of bodily experience with the possible exception of experience (i.e., the habitual body). This "habitual body" might correspond to the concept of "body model" (i.e., the implicit representation of the usual size and shape of one's own body parts), and can be understood as the phenomenological expression of the somatotopic organization of the somatosensory cortex (Longo and Haggard, 2010). It should be acknowledged that the crucial role of individual experience in stabilizing the body model is not incompatible with the existence of a basic, innate organization of the brain acquired through phylogenesis (Longo et al., 2012).

\section{POTENTIAL IMPLICATIONS FOR NEUROREHABILITATION}

As mentioned in the introduction, theoretical options should have implications for clinical practice, especially neurorehabilitation. The structuralist account of bodily experience posits that the latter is an epiphenomenon of both multisensory integration and cognitive processes that are not body-specific. On this ground, future research on clinical syndromes may include extensive testing of both multisensory and cognitive processing. Indeed, setting up therapies implies the upstream demonstration of the level of impairment. In the absence of a consensual, unified framework for the study of bodily experience (de Vignemont, 2010), this would involve thorough testing of cognition and body representation.

Furthermore, two strategies could be tested. The first strategy focusing on multisensory integration would aim at modifying bodily experience by modulating one or several afferent sensory inputs (e.g., enrichment or impoverishment). This corresponds to most of the strategies currently tested based on the now wellestablished role of multisensory integration in bodily experience (e.g., Chokron et al., 2007; Moseley et al., 2008; Diers et al., 2013). A second, complementary strategy based on the interference hypothesis could consist in testing the influence of nonspecific cognitive processes on abnormal bodily experience. This could include, at least, perception (e.g., does modifying the environment of the body modulate bodily experience and improve symptoms?), action (e.g., does tool use action improve symptoms?), language (e.g., does talking and thinking modify bodily experience?), semantics (e.g., does mental imagery of the body improve symptoms in peripheral syndromes? Does the modulation of peripheral afferent information help asemantic patients drawing body parts?), social skills, and emotion (e.g., does the empathy or emotional state of the patient have an impact on symptoms?), and individual experience (e.g., does the intensity of symptoms vary as a function of previous individual habits?).

Furthermore, seeing the extensive list of body-related disorders (de Vignemont, 2010), it seems necessary to test which therapy is effective on which syndrome. For instance, it is unlikely that the same strategies may apply to both peripheral neurological conditions, and syndromes caused by brain lesions. In return, this could lead to categorize body-related disorders depending on which therapy is effective, and hence to better understand the either common or different underlying nature of seemingly different body-related disorders (e.g., if one and the same treatment is effective on both eating disorders and somatoparaphrenia, one might consider that these conditions share a common denominator). Ultimately, neurorehabilitation studies could lead to either confirm or invalidate the hypothesis that bodily experience is an epiphenomenon of multisensory integration and cognition.

\section{CONCLUSION}

The now well-documented permeability of bodily experience and cognitive functioning raises a critical epistemological issue. On a cognitive account of bodily experience, one could argue that body representations exist, and may plastically change during action (Maravita et al., 2003). Nevertheless, if representations are plastic to that point, then one may also wonder what the nature of these representations is, and which specific function they subserve. An alternative structuralist account would be to consider body representations as the consequence rather than the cause of bodily experience and cognition. On this ground, it is proposed that bodily experience is an epiphenomenon of multisensory integration (likely the most body-specific process), and cognition (Figure 1). This is not fully in line with theories of embodied cognition because it amounts to considering that cognition shapes the body as much as the body shapes the mind, whereas embodied cognition accounts generally posit that the body shapes cognition. Demonstrating abnormal bodily experience in the context of completely normal sensory, and cognitive functioning would stand against the hypothesis defended here.

\section{AUTHOR CONTRIBUTIONS}

All authors listed have made a substantial, direct and intellectual contribution to the work, and approved it for publication.

\section{FUNDING}

This work was performed within the framework of the LABEX CORTEX (ANR-11-LABX-0042) of Université de Lyon, within the program Investissements d'Avenir (ANR-11- IDEX-0007; FO) operated by the French National Research Agency (ANR). 


\section{REFERENCES}

Auclair and Jambaqué, 2015 Auclair, L., and Jambaqué, I. (2015). Lexicalsemantic body knowledge in 5- to 11-year-old children : how spatial body representation influences body semantics. Child Neuropsychol. 21, 451-464. doi: 10.1080/09297049.2014.912623

Bonnier, P. (1905). L’Aschématie. Rev. Neurol. 13, 606-609.

Botvinick, M., and Cohen, J. (1998). Rubber hands 'feel' touch that eyes see. Nature 391, 756-756. doi: 10.1038/35784

Breckenridge, J. D., Ginn, K. A., Wallwork, S. B., and McAuley, J. H. (2019). Do people with chronic musculoskeletal pain have impaired motor imagery? a meta-analytical systematic review of the left/right judgment task. J. Pain 20, 119-132. doi: 10.1016/j.jpain.2018.07.004

Buxbaum, L. J. (2001). Ideomotor apraxia : a call to action. Neurocase 7, 445-458. doi: 10.1093/neucas/7.6.445

Calvert, G. A., and Thesen, T. (2004). Multisensory integration : Methodological approaches and emerging principles in the human brain. J. Physiol. Paris 98, 191-205. doi: 10.1016/j.jphysparis.2004.03.018

Chokron, S., Dupierrix, E., Tabert, M., and Bartolomeo, P. (2007). Experimental remission of unilateral spatial neglect. Neuropsychologia 45, 3127-3148. doi: 10.1016/j.neuropsychologia.2007.08.001

De Saussure, F. (1915). Cours de Linguistique Générale. Paris: Payot.

De Vignemont, F. (2007). How many representations of the body? Behav. Brain Sci. 30, 204-205. doi: 10.1017/S0140525X07001434

de Vignemont, F. (2010). Body schema and body image-pros and cons. Neuropsychologia 48, 669-680. doi: 10.1016/j.neuropsychologia.2009.09.022

de Vignemont, F., and Farnè, A. (2010). Incorporer des objets et des membres factices : quelle différence? Revue de Neuropsychol. 2:203. doi: 10.3917/rne.023.0203

Diers, M., Zieglgänsberger, W., Trojan, J., Drevensek, A. M., Erhardt-Raum, G., and Flor, H. (2013). Site-specific visual feedback reduces pain perception: Pain 154, 890-896. doi: 10.1016/j.pain.2013.02.022

Edwards, L. M., Causby, R. S., Stewart, H., and Stanton, T. R. (2019). Differential influence of habitual third-person vision of a body part on mental rotation of images of hands and feet. Exp. Brain Res. 237, 1325-1337. doi: 10.1007/s00221-019-05512-3

Ekiert, M. (2003). The bilingual brain. Work. Papers TESOL Appl. Linguist. 3, 1-8. doi: 10.3171/jns.2004.101.3.0449

Esteves, P. O., Oliveira, L. A. S., Nogueira-Campos, A. A., Saunier, G., Pozzo, T., Oliveira, J. M., et al. (2016). Motor planning of goal-directed action is tuned by the emotional valence of the stimulus : a kinematic study. Sci. Rep. 6:28780. doi: $10.1038 /$ srep 28780

Fodor, J. A. (1983). The Modularity of Mind. Cambridge: MIT Press.

Fuster, J. M. (2009). Cortex and memory : emergence of a new paradigm. J. Cogn. Neurosci. 21, 2047-2072. doi: 10.1162/jocn.2009.21280

Gagnepain, J. (1990). Du vouloir dire. Du Signe, de l'outil. Bruxelles: De Boeck Université.

Goldenberg, G. (1995). Imitating gestures and manipulating a mannikin-the representation of the human body in ideomotor apraxia. Neuropsychologia 33, 63-72. doi: 10.1016/0028-3932(94)00104-W

Goldenberg, G. (2009). Apraxia and the parietal lobes. Neuropsychologia 47, 1449-1459. doi: 10.1016/j.neuropsychologia.2008.07.014

Head, H., and Holmes, H. G. (1911). Sensory disturbances from cerebral lesions. Brain 34, 102-254. doi: 10.1093/brain/34.2-3.102

Hécaen, H., and Ajuriaguerra, J. (1952). Méconnaissances et Hallucinations Corporelles. Paris: Masson.

Isaac, A. R., and Marks, D. F. (1994). Individual differences in mental imagery experience : developmental changes and specialization. Br J. Psychol. 85, 479-500. doi: 10.1111/j.2044-8295.1994.tb 02536.x

Kruse, B., Bogler, C., Haynes, J.-D., and Schütz-Bosbach, S. (2016). Am I seeing myself, my friend or a stranger? the role of personal familiarity in visual distinction of body identities in the human brain. Cortex 83, 86-100. doi: 10.1016/j.cortex.2016.07.010

Lévi-Strauss, C. (1958). Anthropologie Structurale. Paris: Plon.

Linkenauger, S. A., Kirby, L. R., McCulloch, K. C., and Longo, M. R. (2017). People watching : the perception of the relative body proportions of the self and others. Cortex 92, 1-7. doi: 10.1016/j.cortex.2017.03.004
Longo, M. R., and Haggard, P. (2010). An implicit body representation underlying human position sense. Proc. Natl. Acad. Sci.U.S.A. 107, 11727-11732. doi: 10.1073/pnas.1003483107

Longo, M. R., and Haggard, P. (2012a). A 2.5-D representation of the human hand. J. Exp. Psychol. 38, 9-13. doi: 10.1037/a0025428

Longo, M. R., and Haggard, P. (2012b). Implicit body representations and the conscious body image. Acta Psychol. 141, 164-168. doi: 10.1016/j.actpsy.2012.07.015

Longo, M. R., Long, C., and Haggard, P. (2012). Mapping the invisible hand : a body model of a phantom limb. Psychol. Sci. 23, 740-742. doi: $10.1177 / 0956797612441219$

Maravita, A., Spence, C., and Driver, J. (2003). Multisensory integration and the body schema : close to hand and within reach. Curr. Biol. 13, R531-R539. doi: 10.1016/S0960-9822(03)00449-4

Marr, D. (1982). Vision. New York, NY: W.H. Freeman.

Mattioni, S., and Longo, M. R. (2014). The effects of verbal cueing on implicit hand maps. Acta Psychol. 153, 60-65. doi: 10.1016/j.actpsy.2014.09.009

Merleau-Ponty, M. (1945). Phénoménologie de la Perception. Paris: Gallimard.

Moseley, G. L., Parsons, T. J., and Spence, C. (2008). Visual distortion of a limb modulates the pain and swelling evoked by movement. Curr. Biol. 18, R1047-R1048. doi: 10.1016/j.cub.2008.09.031

Osiurak, F. (2014). What neuropsychology tells us about human tool use? the four constraints theory (4CT) : mechanics, space, time, and effort. Neuropsychol. Rev. 30, 88-115. doi: 10.1007/s11065-014-9260-y

Pellencin, E., Paladino, M. P., Herbelin, B., and Serino, A. (2018). Social perception of others shapes one's own multisensory peripersonal space. Cortex 104, 163-179. doi: 10.1016/j.cortex.2017.08.033

Petkova, V. I., Björnsdotter, M., Gentile, G., Jonsson, T., Li, T.-Q., and Ehrsson, H. H. (2011a). From part- to whole-body ownership in the multisensory brain. Curr. Biol. 21, 1118-1122. doi: 10.1016/j.cub.2011.05.022

Petkova, V. I., and Ehrsson, H. H. (2008). If i were you : perceptual illusion of body swapping. PLoS ONE 3:e3832. doi: 10.1371/journal.pone.0003832

Petkova, V. I., Khoshnevis, M., and Ehrsson, H. H. (2011b). The perspective matters! multisensory integration in ego-centric reference frames determines full-body ownership. Front. Psychol. 2:35. doi: 10.3389/fpsyg.2011.00035

Proffitt, D. R. (2006). Embodied perception and the economy of action. Perspect. Psychol. Sci. 1, 110-122. doi: 10.1111/j.1745-6916.2006.00008.x

Ramachandran, V. (1998). The perception of phantom limbs. the D. O. Hebb lecture. Brain 121, 1603-1630. doi: 10.1093/brain/121.9.1603

Sabouraud, O. (1995). Le langage et Ses Maux. Paris: Jacob.

Sachse, P., Beermann, U., Martini, M., Maran, T., Domeier, M., and Furtner, M. R. (2017). "The world is upside down" - the innsbruck goggle experiments of theodor erismann (1883-1961) and ivo kohler (1915-1985). Cortex 92, 222-232. doi: 10.1016/j.cortex.2017.04.014

Salvato, G., Peviani, V., Scarano, E., Scarpa, P., Leo, A., Redaelli, T., et al. (2017). Dissociation between preserved body structural description and impaired body image following a pediatric spinal trauma. Neurocase 23, 149-153. doi: 10.1080/13554794.2017.1332227

Schwartz, J., Sato, M., and Fadiga, L. (2008). The common language of speech perception and action: a neurocognitive perspective. Rev. Franc. Linguist. Appli. 13, 9-22. Available online at: https://www.cairn.info/revue-francaise-delinguistique-appliquee-2008-2-page- 9 .htm

Schwoebel, J., and Coslett, H. B. (2005). Evidence for multiple, distinct representations of the human body. J. Cogn. Neurosci. 17, 543-553. doi: 10.1162/0898929053467587

Shebani, Z., and Pulvermüller, F. (2018). Flexibility in language action interaction : the influence of movement type. Front. Hum. Neurosci. 12:252. doi: 10.3389/fnhum.2018.00252

Sirigu, A., Grafman, J., Bressler, K., and Sunderland, T. (1991). Multiple representations contribute to body knowledge processing : evidence from a case of autotopagnosia. Brain 114, 629-642. doi: 10.1093/brain/114. 1.629

Ursino, M., Cuppini, C., and Magosso, E. (2014). Neurocomputational approaches to modelling multisensory integration in the brain : a review. Neural Netw. 60, 141-165. doi: 10.1016/j.neunet.2014.08.003

Vallila-Rohter, S., and Kiran, S. (2015). An examination of strategy implementation during abstract nonlinguistic category learning in aphasia. J. Speech Lang. Hear. Res. 58, 1195-1209. doi: 10.1044/2015_JSLHR-L-14-0257 
Vingerhoets, G., Alderweireldt, A.-S., Vandemaele, P., Cai, Q., Van der Haegen, L., Brysbaert, M., et al. (2013). Praxis and language are linked : evidence from co-lateralization in individuals with atypical language dominance. Cortex 49, 172-183. doi: 10.1016/j.cortex.2011.11.003

Wiener, S. I. (1996). Spatial, behavioral and sensory correlates of hippocampal CA1 complex spike cell activity : implications for information processing functions. Prog. Neurobiol. 49, 335-361. doi: 10.1016/0301-0082(96)00019-6

Yau, J. M., DeAngelis, G. C., and Angelaki, D. E. (2015). Dissecting neural circuits for multisensory integration and crossmodal processing. Philos. Trans. R. Soc. B: Biol. Sci. 370:20140203. doi: 10.1098/rstb.2014.0203
Conflict of Interest Statement: The authors declare that the research was conducted in the absence of any commercial or financial relationships that could be construed as a potential conflict of interest.

Copyright () 2019 Baumard and Osiurak. This is an open-access article distributed under the terms of the Creative Commons Attribution License (CC BY). The use, distribution or reproduction in other forums is permitted, provided the original author(s) and the copyright owner(s) are credited and that the original publication in this journal is cited, in accordance with accepted academic practice. No use, distribution or reproduction is permitted which does not comply with these terms. 